\title{
Going back to the drawing board
}

Harnessing the potential of the design process to effectively change organizational routines

Many organizations face
challenges when trying to
create effective and lasting
strategic change. r Vern
Glaser, Associate Professor in
the Department of Strategy,
Entrepreneurship and
Management at the University
of Alberta, studies how
organizations change their
routines to accomplish strategic
objectives.
In his paper "Design
Performances: How
Organizations Inscribe Artifacts
to Change Routines", Dr
Glaser r resents a case study
of how a law enforcement
agency designed an algorithm
to optimize officers' patrolling
routines, thereby detering
criminal activity. His study reveals
the importance of the design
process in facilitating change-an
aspect that often is overlooked in
theory and in practice.

to improve their performance to improve their performance a change initiative may be even more In tortant han defining the right goal of steps necessary to solve a problem study of a lawe nforcement agency reveals or guesswork. Algorithms always work regardless of the inputs, and may take the form of software, procedures, and/ or scripts. For example, Amazon and Netflix use machine learning algorithm to generate automated recommendations about products or services for customers: Proctor \& Gamble and other consumer products companies use text analysis algorithms to monitor consumer brand engagement on social media; and shipping companies such as UPS and FedEx use optimization algorithms minimize delivery costs.

When implementing large-scale strategic change initiatives, organizations tend to the "right" objectives and selecting the "right" algorithms to achieve them. However, in "Design Performances: How Organizations Inscribe Artifacts to Chang Routines", Dr Vern Glaser, Associate Professor at the University of Alberta

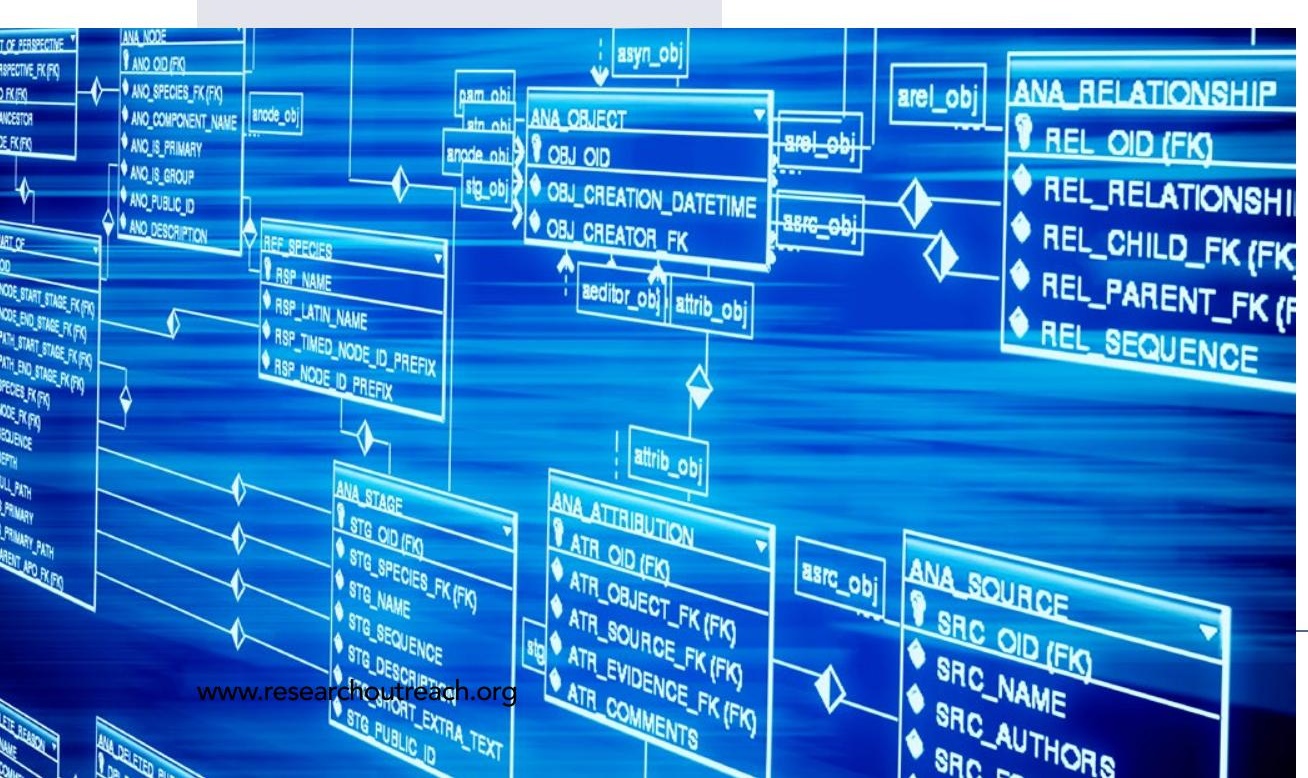
change patrolling routines with the

Dr Glaser presents a case study of how a law
enforcement agency designed an algorithm to optimize officers' patrolling routines, thereby

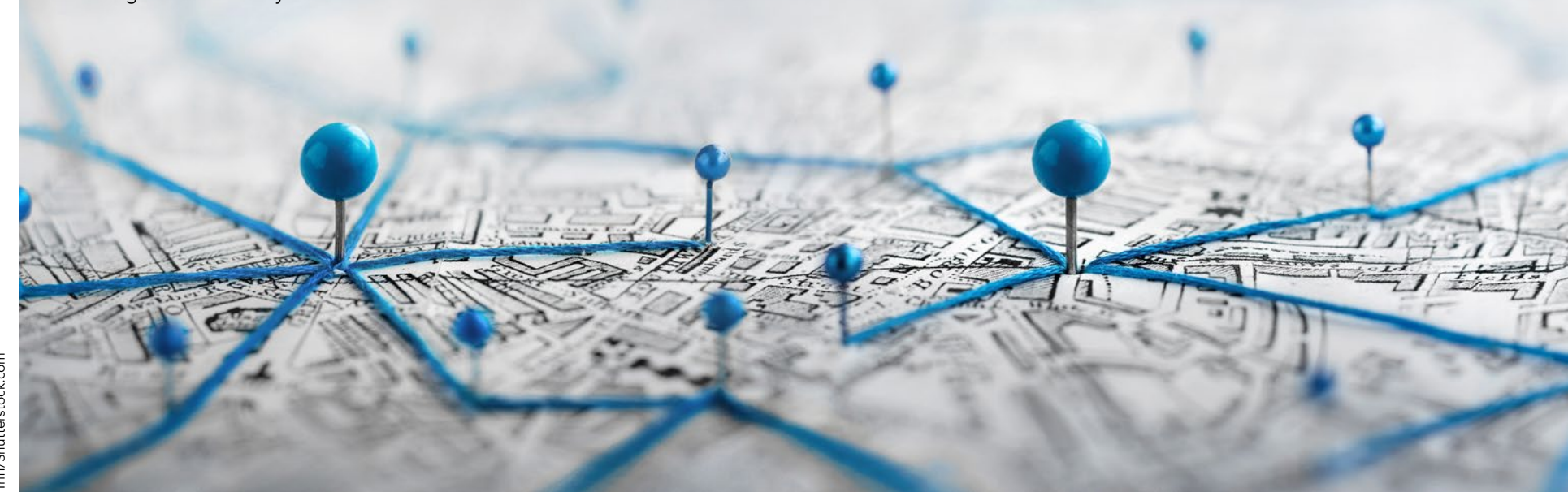

to make it more difficult for terrorists o realise a successful altack, Metropo deploying available resources such as officers to different locations. Upon their arrival, officers would observe activities, query individuals or look for suspicious materials, such as abandoned backpacks. Likewise, to deter fare evasion, Metropol periodically deployed deputy officers and security assistants to transit stations, trains, and buses to

for fare payment

and issue warning

and citations

to passengers

without valid fare ALGORITHM TO CHANGE ORGANIZATHONAL ROUTINES: THE CASE OF METROPOL W Western United States (ie Metropol, a pseudonym) designed software to objective of deterring criminal activityspecifically, terrorism and fare evasion on public transport. Organizational actors partnered with Algo-Security, a research firm dedicated to developing eal-world security solutions, to desig a tool that used a game-theoretic algorithm to predict criminal activity and automatically adjust patrolling routines based on those predictions.

Metropol's existing patrolling routines were determined by schedulers who used an Excel spreadsheet to assign . patrol units, K-9 units, and plainclothes

agencies. The design process involved four core activites. (a) identifying essen questioning underlying assumptions: (c) redistributing the work; and (d) rethinking performance metrics.

IDENTIFYING ESSENTIAL COMPONENTS OF THE EXISTING ROUTINE

To design a tool that used an algorithm to eam had to identify all components protected by routine (e.g., locations number of available security resources, activities that those resources could perform, and the amount of time it takes to perform those activities) and translate them into knowledge that could be embedded as parameters in the algorithmic software application. For example, the algorithm needed consider tacit knowledge, such as audit passengers

The project team had to identify all the components of the existing routine and translate them into knowledge that could be embedded as algorithmic parameters.

Metropol becan

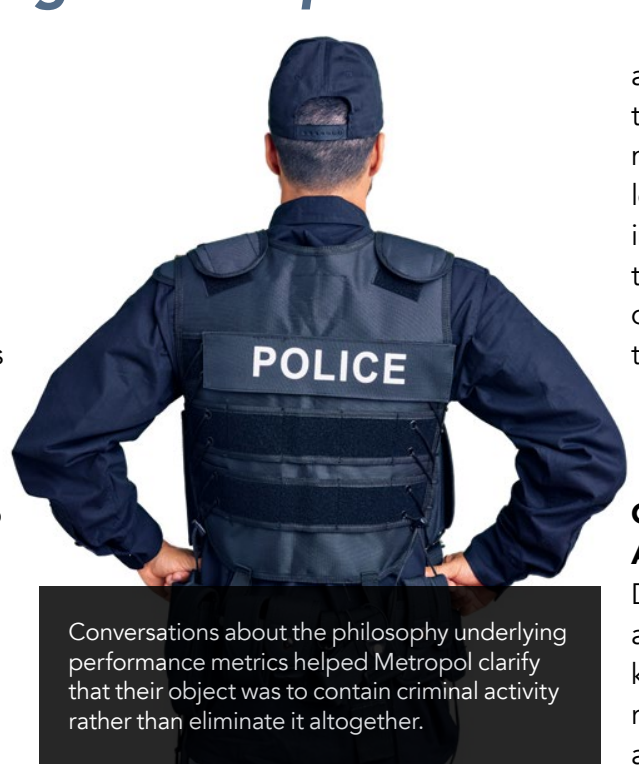

travel time to a patrolling

destination, and the

relative attractiveness of each location to criminals. bus or train station, law question individuals in the station (15 minutes), observe any action (10 minutes) pass through the station en route to another one (10 minutes), or move between different levels of a station (1 minute). It was mportant to comprehensively identify the core components (i.e., resources deployed, location, travel time, action ime) of the routine, and translate these ssential components into algorithmic parameters.

\section{QUESTIONING UNDERLYING} ASSUMPTIONS During the design process, Metropol and Algo-Security interrogated the key assumptions built into existing outines. The game-theoretic 
